\title{
Does Supporting the Luteal Phase With Progesterone Only Without Estradiol Can Affect the Pregnancy Outcome in In-Vitro Fertilization Cycles?
}

MONA M.B. RASHED, M.Sc.; SHAHINAZ H. ELSHORBAGY, M.D.; TAREK M.E. EL HAWARY, M.D. and MANAL M. ABDALLAH, M.D.

The Department of Obstetrics \& Gynecology, Faculty of Medicine, Tanta University

\begin{abstract}
Background: It is well established that luteal support with progesterone improves implantation in IVF cycles. Unfortunately, there are conflicting reports regarding the value of luteal phase estradiol supplementation on pregnancy rates.

Aim of Study: To compare the pregnancy rate if we use progesterone only versus the use of progesterone and estradiol as a luteal phase support in IVF cycles.

Study Design and Setting: A prospective randomized clinical trial.

Patients and Methods: This study has been carried out in Tanta University Hospital in co-ordination with private IVF centers in the period from October 2017-to June 2018.

This study included 60 women divided into two group:

- Group I consists of 30 patients who received vaginal administration of progesterone supplementation in the form of $400 \mathrm{mg}$ prontogest twice a day.

- The second group consists of 30 patient in which $2 \mathrm{mg}$ estradiol valerate twice daily with prontogest suppositories has been used.

Results: The findings suggest that the pregnancy rate is higher with the estrogen and progesterone supplementation than the progesterone only supplementation in both groups who have used GnRH agonist or antagonist controlled ovarian stimulation protocol but it has not reached a statistically significant value.
\end{abstract}

Conclution: Supplementary administration of E2 to $p$ for luteal phase support may be beneficial for better IVF outcome and it warrants further investigation.

Key Words: Estrogen - IVF - Luteal phase support-Progesterone.

Correspondence to: Dr. Mona M.B. Rashed, The Department of Obstetrics \& Gynecology, Faculty of Medicine, Tanta University

\section{Introduction}

SEVERAL factors including oocyte quality and receptivity of endometrium influence the success of in vitro fertilization cycles. Implantation of the embryo is critical in determining the success of assisted reproductive techniques because after the transfer of high quality embryos, the pregnancy rate may still be relatively low [1]

Normal luteal function is essential for establishment and maintenance of pregnancy. In stimulated in vitro fertilization cycles, however the supra physiological hormone levels present are associated with a defective luteal phase in almost all patients. In attempt to enhance the probability of pregnancy, different doses, durations, and types of treatment for luteal phase support have been evaluated, however there is still no agreement regarding the optimal supplementation scheme to be used [2]

The addition of progesterone and human chorionic gonadotropin with the aim of luteal support has been shown to increase pregnancy rates in many randomized studies; on the other hand ideas about using estradiol for luteal phase support are conflicting. Some reports favored the addition of estradiol supplementation, whereas others failed to observe any beneficial effects [3] .

\section{Patients and Methods}

This study is conducted on 60 patients:

The included 60 patients have been recruited with the following criteria:

- Infertile women undergoing in vitro fertilization.

- Body mass index $<28 \mathrm{KG} / \mathrm{m}^{2}$.

- Age $<40$ year. 
All the following patients have been excluded from the study:

- Basal FSH >12IU/1.

- Abnormal thyroid function.

- Hyperprolactinaemia.

- Endometriosis.

- Uterine anomalies.

-We also have excluded patients with severe male factor or previous 2 or more failed IVF trials from the study.

- Group IA consists of 15 patients who have received luteal support by progesterone only and have received agonist protocol for $\mathrm{COH}$.

- Group IB consists of 15 patients who have received luteal support by progesterone only and have received antgonist protocol for $\mathrm{COH}$.

- Group IIA consists of 15 patients who have received luteal support by estrogen and progesterone and have received agonist protocol for $\mathrm{COH}$.

- Group IIB consists of 15 patients who have received luteal support by estrogen and progesterone and have received antgonist protocol for $\mathrm{COH}$.

\section{In GnRH agonist protocol:}

All patients have underwent pituitary downregulation by daily injection of $0.1 \mathrm{mg}$ of $\mathrm{GnRH}$ agonist (Decapeptyl, ferring) starting in the 21 st day of previous cycle for at least 2 weeks prior to ovarian stimulation. When down-regulation occurs as shown from estradiol level $<50 \mathrm{pg} / \mathrm{ml}$ and no ovarian follicle $>10 \mathrm{~mm}$, ovarian stimulation has been initiated by daily injections (1 50-375IU) of human menopausal gonadotropin (HMG; Merional, lbsa) I.m. and (1 50-375IU) of recombinant FSH (RecFSH; Gonal. F) s.c. The dose is determined according to age, BMI, follicular phase, serum FSH level, AFC, AMH level and previous history of ovarian response if there had been a treatment. When at least three follicles $>18 \mathrm{~mm}$ have been observed on transvaginal ultrasonography, all medication has been stopped and 1 0000IU human chorionic gonadotropin (choriomon, ibsa) have been administered by i.m. injection in order to complete oocyte maturation. Oocyte retrieval has taken place 34-36h after HCG administration.

\section{In GnRH antagonist protocol:}

Daily gonadotropin stimulation has been started on the $2^{\text {nd }}$ or the $3^{\text {rd }}$ day of menstrual cycle; the starting dose has been determined (ranging from 150-375iu) of human menopausal gonadotropin (HMG; Merional, lbsa) I.M and (1 50-375IU) of recombinant FSH (RecFSH; Gonal f) s.c. The dose is determined according to age, BMI, follicular phase, serum FSH level and previous history of ovarian response if there had been a treatment. GnRH antagonist injections at a dose of $0.25 \mathrm{mg} /$ day have been started when the leading follicle reached $14 \mathrm{~mm}$. Gonadotropin dosage have been adjusted according to ovarian response on day 5 . Pelvic ultrasound and endocrine monitoring have been performed thereafter. Injections have been continued until $>3$ follicles have reached $>18 \mathrm{~mm}$ diameter. At that time $0.2 \mathrm{mg}$ Decapeptyl has been given for triggering or $10000 \mathrm{IU}$ of $\mathrm{HCG}$ according to case condition. Transvaginal oocyte retrieval has been performed 34-36h after triggering.

\section{Procedure of oocyte retrieval:}

Oocytes have been retrieved 34-36h after triggering and have been fertilized in vitro.

\section{Procedure for embryo transfer:}

- ET was carried out 2-5 day after oocyte retrieval. A maximum of 3 embryos were transferred into each patient.

- Clinical pregnancy was defined as elevated serum beta HCG 14 days after ET and presence of gestational sac (s) by transvaginal $\mathrm{u} / \mathrm{s}$ which was done 1 week after the onset of last menstrual period.

\section{Results}

Table (1): Demographic characteristics in the four studied groups.

\begin{tabular}{lcccc}
\hline & Range & Mean \pm SD & F.test & $p$-value \\
\hline Age (years): & & & & \\
Group IA & $23-35$ & $28.20 \pm 3.88$ & 1.340 & 0.271 \\
Group IIA & $21-37$ & $28.00 \pm 4.83$ & & \\
Group IB & $19-37$ & $27.67 \pm 4.64$ & & \\
Group IIB & $19-32$ & $25.47 \pm 3.42$ & & \\
BMI $($ Kg/m2): & & & & \\
Group IA & $19-31$ & $23.13 \pm 3.64$ & 1.220 & 0.311 \\
Group IIA & $19-35$ & $25.20 \pm 4.33$ & & \\
Group IB & $20-35$ & $25.13 \pm 4.45$ & & \\
Group IIB & $18-37$ & $26.00 \pm 4.63$ & & \\
Duration of infertility & & & & \\
(years): & & & & \\
Group IA & $2-16$ & $4.97 \pm 3.53$ & 0.793 & 0.503 \\
Group IIA & $1-10$ & $4.23 \pm 2.56$ & & \\
Group IB & $1-16$ & $5.67 \pm 3.62$ & & \\
Group IIB & $1-7$ & $4.27 \pm 1.67$ & & \\
\hline
\end{tabular}

Table (1) shows that the four groups are homogenous as regarded age, BMI, duration of infertility. 
Table (2): Days of stimulation, dose of gonadotropins, number of oocytes retrieved, MII oocytes and embryos transferred in the studied groups.

\begin{tabular}{|c|c|c|c|c|}
\hline & Range & Mean \pm SD & F.test & $p$-value \\
\hline \multicolumn{5}{|c|}{ Days of stimulation: } \\
\hline Group IA & $8-13$ & $10.60 \pm 1.18$ & 6.442 & $0.001 *$ \\
\hline Group IIA & $9-13$ & $10.33 \pm 0.90$ & & \\
\hline Group IB & $8-11$ & $9.20 \pm 0.94$ & & \\
\hline Group IIB & $8-11$ & $9.87 \pm 0.64$ & & \\
\hline \multicolumn{5}{|l|}{ Dose of } \\
\hline \multicolumn{5}{|c|}{ gonadotropins (iu): } \\
\hline Group IIA & $1350-4125$ & $2336.80 \pm 714.89$ & 4.530 & $0.006^{*}$ \\
\hline Group IB & $1500-3000$ & $2255.00 \pm 497.06$ & & \\
\hline Group IIB & $1200-3300$ & $2125.00 \pm 740.66$ & & \\
\hline \multicolumn{5}{|l|}{ Oocytes: } \\
\hline Group IA & $3-24$ & $13.20 \pm 5.89$ & 4.985 & $0.004 *$ \\
\hline Group IIA & $6-26$ & $13.60 \pm 6.16$ & & \\
\hline Group IB & $2-25$ & $9.93 \pm 5.40$ & & \\
\hline Group IIB & $2-13$ & $7.07 \pm 3.35$ & & \\
\hline \multicolumn{5}{|l|}{ MII oocytes: } \\
\hline Group IA & $1-25$ & $7.47 \pm 5.89$ & 2.980 & $0.039 *$ \\
\hline Group IIA & $3-15$ & $9.47 \pm 3.66$ & & \\
\hline Group IB & $2-11$ & $4.87 \pm 2.95$ & & \\
\hline Group IIB & $2-15$ & $6.87 \pm 3.93$ & & \\
\hline \multicolumn{5}{|c|}{$\begin{array}{l}\text { Number of embros } \\
\text { transferred: }\end{array}$} \\
\hline Group IA & $1-4$ & $2.67 \pm 1.05$ & 0.827 & 0.485 \\
\hline Group IIA & $2-3$ & $2.60 \pm 0.51$ & & \\
\hline Group IB & $1-3$ & $2.47 \pm 0.64$ & & \\
\hline Group IIB & $1-3$ & $2.27 \pm 0.70$ & & \\
\hline
\end{tabular}

Table (2) shows that days of stimulation and dose of gonadotropins are significantly higher in Group IA (progesterone only agonist group) and Group IIA (estrogen and progesterone agonist group).

The number of oocytes retrieved and metaphase II oocytes are significantly higher in Group IIA (estrogen and progesterone agonist group) and Group IA (progesterone only agonist group).

There is no significant difference between the studied groups in the number of embryos transeferred.

Table (3): Pregnancy rate in the studied groups.

\begin{tabular}{llllll}
\hline \multicolumn{5}{c}{ Group IA Group IIA } & \multicolumn{5}{l}{ Group IB Group IIB Total } \\
\hline HCG positive: & & & & 10 & 31 \\
$\mathrm{~N}$ & 7 & 9 & 5 & 66.7 & 51.7 \\
$\%$ & 46.7 & 60.0 & 33.3 & 66 & \\
HCG negative: & & & & & \\
$\mathrm{N}$ & 8 & 6 & 10 & 5 & 29 \\
$\%$ & 53.3 & 40.0 & 66.7 & 33.3 & 48.3 \\
Total: & & & & & \\
$\mathrm{N}$ & 15 & 15 & 15 & 15 & 60 \\
$\%$ & 100.0 & 100.0 & 100.0 & 100.0 & 100.0 \\
Chi-square: & & & & & \\
$\chi^{2}$ & & & 3.938 & & \\
$p$-value & & & 0.268 & & \\
\hline
\end{tabular}

Table (3) shows that the pregnancy rate it is $66.7 \%, 60 \%, 46.7 \%, 33.3 \%$ in Group IIB, IIA, IA and IB respectively. So it is higher in Group IIB (antagonist $\mathrm{E}$ and $\mathrm{P}$ ) and Group IIA (agonist $\mathrm{E}$ and P) but dose not reach the statistical significance.

\section{Discussion}

It was initially assumed that the LPD after IVF resulted from destruction of granulosa cells designed to become the CL during oocyte aspiration. This theory was questioned after no changes in progesterone levels or luteal phase length were seen after aspiration of the single mature follicle in a natural, unstimulated cycle [4]

The administration of HCG to mimic the LH surge in IVF has been implicated as a cause of LPD by inhibition endogenous LH secretion from the pituitary. However, normal luteal phase length and pregnancy rates are routinely seen in women receiving HCG triggers in natural cycles or while undergoing superovulation and intrauterine insemination [5]

Other investigators have posited that the LPD is the result of GnRH agonist used to down regulate pituitary LH secretion, suppressing LH secretion well into the luteal phase. With the advent of GnRH antagonists, which clear quickly and do not cause long-term pituitary LH suppression, premature luteolysis and poor pregnancy rates were seen when used during IVF cycles without progesterone support, illustrating prolonged $\mathrm{GnRH}$ agonist pituitary suppression cannot be the sole cause of LPD in women undergoing IVF [6].

Currently, the most widely accepted theory of LPD after IVF states the supraphysiologic steroid hormones secreted by the multiple CL in the early luteal phase of an IVF cycle causes direct inhibition of LH secretion via negative feedback on the hypothalamic-pituitary axis [7].

In this study we have compared the luteal phase support with progesterone only with the luteal support with estrogen and progesterone in agonist and antagonist groups.

As regard baseline characteristics of the patients there are no significant differences between the studied groups in the mean age, body mass index, duration of infertility, primary cause of infertility, baseline serum FSH levels and AMH level confirming the validity of randomization.

In our study days of Stimulation and dose of gonadotropins are significantly higher in Group 
IA and IIA. And the highest number of M II oocytes and oocytes retrieved is in Group IIA and IA.

This is not agreed by the study of Tesarik et al., in which the ovarian stimulation cycle characteristics of patients treated with the GnRH antagonist and patients treated with the long GnRH agonist showed no significant differences between the groups [8].

The findings suggest that the pregnancy rate is higher with the estrogen and progesterone supplementation than the progesterone only supplementation in both groups who have used GnRH agonist or antagonist controlled ovarian stimulation protocol but it has not reached a statistically significant value.

Smitz et al., showed that serum E2 concentrations drop at the end of the luteal phase, the idea that E2 should be used throughout the luteal phase in IVF cycles emerged [9].

Abdel-Moneim et al., showed that estradiol level declines in the midluteal phase, patients could benefit from adding estradiol to progesterone in LPS, and at that time the effect of hCG used for ovulation triggering on the corpus luteum decreases. The benefit includes an increase in the probability of pregnancy.

The benefit of additional luteal supplementation with E2 is controversial. Where luteal long agonist protocol was started in the mid luteal phase of the preceding cycle for $\mathrm{COH}$ and $4 \mathrm{mg}$ oral estradiol valerate tablets were given from day 7 post-transfer in addition to progesterone which was started after oocyte retrieval. It was given empirically whatever the level of mid luteal estradiol. There was a better implantation and clinical pregnancy rate in the $\mathrm{E}$ and $\mathrm{P}$ group than the $\mathrm{P}$ only group but not statistically significant [10]

Lukaszuk et al., used long protocol of pituitary suppression with the GnRH agonist demonstrated significantly higher PRs and implantation rates in the E2 P group compared with the P-only group [11].

The addition of E2 to the progestin support in long GnRH agonist protocol regimen may have a beneficial effect on pregnancy and implantation rates [12]

In the study of Ghanem et al., who used long agonist protocol for $\mathrm{COH}$, the clinical pregnancy and implantation ratio was statistically significant in the E2 P group compared with the P-only group.
And they conclude that adding oral E2 (or IM hCG) to $\mathrm{P}$ in the luteal phase support for long GnRH-a protocol IVF/ICSI cycles results in better biochemical hormone profile, which is translated into better clinical cycle outcome as shown by higher IRs and PRs and lower miscarriage rates [13].

However, Elgindy et al., studied the role of luteal estradiol supplementation in long agonist cycles and found that when E2 valerate was taken orally, the PRs were higher than in the P-only group, but the difference was not statistically significant [14]

In IVF cycles with GnRH agonist, supplementing $\mathrm{P}$ with $4 \mathrm{mg}$ of oral $\mathrm{E} 2$ in the luteal phase significantly increased the PRs and implantation rates and decreased the miscarriage rate compared with the use of $\mathrm{P}$ alone. Although supplementing $\mathrm{P}$ with hCG as a luteal support also yielded similar results to E2, the latter should be preferred because of OHSS and multiple-pregnancy risks [15]

The combined data presented in the metaanalysis done by Jee et al., suggested that there were no statistically significant differences between E2 P versus P-only group regarding overall IVF outcomes. From seven studies including GnRH agonist cycles, no statistical significant differences were found between the two groups in clinical PR. from three studies including GnRH antagonist cycles only were all similar between the two groups [16].

Although Jee et al., Gelbaya et al., and Kolibianakis et al.), confirmed that the addition of E2 to $\mathrm{P}$ for luteal phase support in IVF cycles has no beneficial effect on PR, it is still unclear whether the effect of E2 supplementation is dependent on the dosage or route of administration [15-17]

In the nine studies included in the meta-analysis of Jee et al., E2 and even P was supplemented by various routes of administration; therefore more sophisticated study would be needed to clarify the effect of E2 supplementation [16]

Earlier reports indicate that clinical PRs were consistently similar between groups with added 6 mg (Smitz et al.) or $2 \mathrm{mg}$ (Lewin et al.) E2. However, one recent randomized trial demonstrated a significantly higher clinical PR in $6 \mathrm{mg}$ E2 supplement group but not in $2 \mathrm{mg}$ group compared with no E2 group [18].

The debate on E2 supplementation mainly stems from midluteal decline of serum E2 and its impact on endometrial receptivity. 
Despite the insignificant role proven by several meta-analyses of routine E2 supplementation during the entire luteal phase in IVF cycles, it remains to be determined whether the supplementation is beneficial to a specific group of IVF patients [16]

\section{Conclusion:}

Supplementary administration of E2 to $\mathrm{P}$ for luteal phase support may be beneficial for better IVF outcome. There is a need for further RCTs that will assess the effect of estrogen addition to progesterone during the luteal phase on the probability of pregnancy.

\section{References}

1- MOINI A., ZADEH MODARRESS S., AMIRCHAGHMAGHI E., MIRGHAVAM N., KHAFRI S. and REZA AKHOOND M. SALMAN YAZDI R.: The effect of adding oral oestradiol to progesterone as luteal phase support in ART cycles-a randomized controlled study. Arch. Med. Sci., Feb., 7 (1): 112-6, 2011.

2- FATEMI H.M., POPOVIC-TODOROVIC B., PAPANIKOLAOU E., DONOSO P. and DEVROEY P.: An update of luteal phase support in stimulated IVF cycles. Hum. Reprod Update, 13 (6): 581-90, 2007.

3- VAR T., TONGUC E.A., DOGANAY M., GULERMAN C., GUNGOR T. and MOLLAMAHMUTOGLU L.: A comparison of the effects of three different luteal phase support protocols on in vitro fertilization outcomes: A randomized clinical trial. Fertil Steril, Mar. 1, 95 (3): 985-9, 2011.

4- KERIN J.F., BROOM T.J., RALPH M.M., KERIN J.F., BROOM T.J., RALPH M.M., EDMONDS D.K. WARNES G.M., JEFFREY R., CROCKER J.M., et al.: Human luteal phase function following oocyte aspiration from the immediately preovular graafian follicle of spontaneous ovular cycles. Br. J. Obstet. Gynaecol., 88: 10218,1981 .

5- SMITZ J., ERARD P., CAMUS M., DEVROEY P., TOUR NAYE H., WISANTO A. and VAN STEIRTEGHEM A.C.: Pituitary gonadotrophin secretory capacity during the luteal phase in superovulation using GnRH-agonists and HMG in a desensitization or flare-up protocol. Hum. Reprod., 7: 1225-9, $1992 \mathrm{~b}$.

6- BECKERS N.G., MACKLON N.S., EIJKEMANS M.J., LUDWIG M., FELBERBAUM R.E., DIEDRICH K., BUSTION S., LOUMAYE E. and FAUSER B.C.: Nonsupplemented luteal phase characteristics after the administration of recombinant human chorionic gonadotropin, recombinant luteinizing hormone, or gonadotropinreleasing hormone (GnRH) agonist to induce final oocyte maturation in in vitro fertilization patients after ovarian stimulation with recombinant follicle-stimulating hormone and GnRH antagonist cotreatment. J. Clin. Endocrinol. Metab., 88: 4186-92, 2003.

7- MESEN T.B. and YOUNG S.L.: Progesterone and the Luteal Phase Obstet. Gynecol. Clin. North Am., 42 (1): $135-51,2015$
8- TESARIK J.1., HAZOUT A. MENDOZA-TESARIK R., MENDOZA N. and MENDOZA C.: Beneficial effect of luteal-phase GnRH agonist administration on embryo implantation after ICSI in both GnRH agonist-and antagonist-treated ovarian stimulation cycles. Hum. Reprod., Oct., 21 (10): 2572-9, 2006.

9- SMITZ J., DEVROEY P., BRAECKMANS P., CAMUS M., KHAN L., STAESSEN C., et al.: Management of failed cycles in an IVF/GIFT programme with the combination of a Gnrh analogue and HMG. Hum. Reprod, 2: 309-14, 1987.

10- ABDEL-MONEIMA M., EL-AGWANYA A. and ABO ALI A.: Is There a Role for Estradiol With Progesterone in Luteal Phase Support With Intracytoplasmic Sperm Injection Cycles? A Retrospective Controlled Study With Reviewing the Literature. J. Clin. Gynecol. Obstet., 4 (2): 226-31, 2015

11- FARHI J., WEISSMAN A., STEINFELD Z., SHORER M., NAHUM H. and LEVRAN D.: Estradiol supplementation during the luteal phase may improve the pregnancy rate in patients undergoing in vitro fertilization-embryo transfer cycles. Fertil Steril, 73: 761-6, 2000.

12- GHANEM M.E., SADEK E.E., ELBOGHDADY L.A. HELAL A.S., GAMAL A., ELDIASTY A., BAKRE N.I. and HOUSSEN M.: The effect of luteal phase support protocol on cycle outcome and luteal phase hormone profile in long agonist protocol intracytoplasmic sperm injection cycles: A randomized clinical trial. Fertil Steril, 92: 486-93, 2009.

13- ELGINDY E.A., EL-HAIEG D.O., MOSTAFA M.I. and SHAFIEK M.: Does luteal estradiol supplementation have a role in long agonist cycles? Fertil Steril, 93: 2182-8, 2010.

14- VAR T., TONGUC E.A., DOGANAY M., GULERMAN C., GUNGOR T. and MOLLAMAHMUTOGLU L.: A comparison of the effects of three different luteal phase support protocols on in vitro fertilization outcomes: A randomized clinical trial. Fertil Steril., Mar. 1, 95 (3): 985-9, 2011.

15- JEE B.C., SUH C.S., KIM S.H., KIM Y.B. and MOON S.Y.: Effects of estradiol supplementation during the luteal phase of in vitro fertilization cycles: A meta-analysis. Fertil Steril, 93: 428-36, 2010.

16- GELBAYA T.A., KYRGIOU M., TSOUMPOU I. and NARDO L.G.: The use of estradiol for luteal phase support in invitro fertilization/intracytoplasmic sperm injection cycles: A systematic review and meta-analysis. Fertil Steril, 90: 2116-25, 2008.

17- KOLIBIANAKIS E.M., VENETIS C.A., PAPANIKOLAOU E.G., DIEDRICH K., TARLATZIS B.C. and GRIESINGER G.: Estrogen addition to progesterone for luteal phase support in cycles stimulated with GnRH analogues and gonadotrophins for IVF: A systematic review and meta-analysis. Hum. Reprod., 23: 1346-54, 2008 .

18- LUKASZUK K., LISS J., LUKASZUK M. and MAJ B.: Optimization of estradiol supplementation during the luteal phase improves the pregnancy rate in women undergoing in vitro fertilization-embryo transfer cycles. Fertil Steril, 83: 1372-6, 2005. 


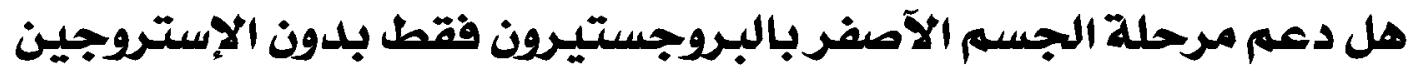

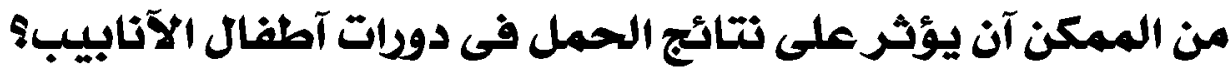

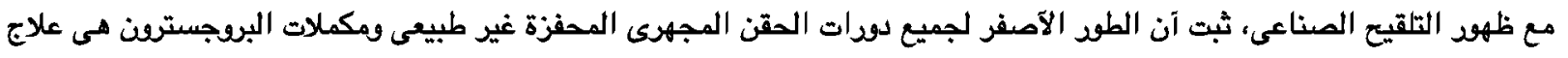

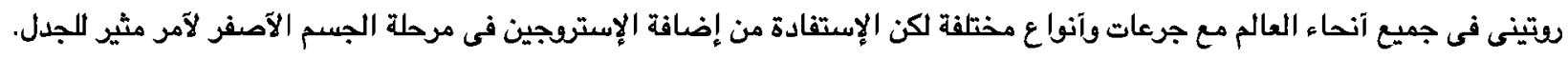
المرضى والطريقة: شملت هذه الدراسة .7 إمرآة إلى مجموعتين:

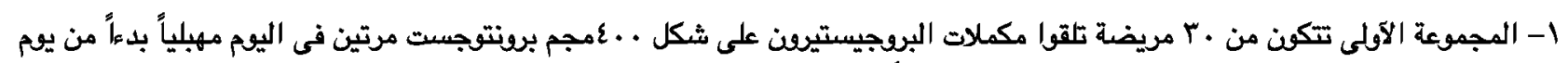

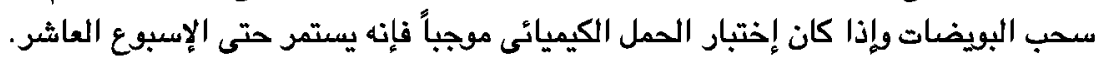

r- المجموعة الثانية تتكون من • ب مريضة حيث تبدآ بملغ إستراديول فاليرات مرتين يومياً مع تحاميل البرنتوجست فى يوم سحب البويضات

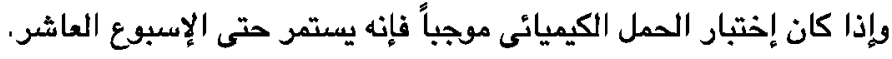

$$
\text { تم تقسيم كل مجموعة إلى مجموعتين: }
$$
آ- كان تحفيز المبيض ببروتوكمل مماثلات هرمون مربسل الجونادوتروبين. ب- تم تنفيذ التحفيز المبيض بواسطة بروتوكل مضادات هرمون مرسل الجونادوتروبين. النتائج: تثير النتائج إلى آن معدل الحمل آعلى مع مكملات الإستروجين والبرجبستيرن من إضافة البروجسترون فقط فى كلا المجموعتين الذين خضعوا لبوتوكل مماثلات ومضادات هرمون مرسل الجونادوترويين ولكن لم يصل إلى قيمة ذات دلالة إحصائية. 